\title{
A ressignificação do ensino de línguas a partir do uso intensivo das TDIC em tempos de pandemia
}

\author{
The redefinition of languages teaching from the intensive use of DTIC in times of \\ pandemic
}

\section{La redefinición de la enseñanza de idiomas a partir del uso intensivo de las TDIC en tiempos de pandemia}

\author{
Jéssica Mary Costa do Rosário ${ }^{1}$ \\ Ana Emilia Fajardo Turbin ${ }^{2}$
}

\section{Resumo}

A pandemia gerada pela Covid-19 mostrou a importância da inserção das Tecnologias Digitais de Informação e Comunicação (TDIC) no âmbito educacional; a formação de professores requer, portanto, cada vez mais preparo para um efetivo trabalho docente. A Base Nacional Comum para a Formação Inicial de Professores de Educação Básica (BNCFormação), em sintonia com a Base Nacional Comum Curricular (BNCC), reconhece a necessidade de empregar pedagogicamente as inovações e as linguagens digitais no ensino. $\mathrm{O}$ uso das TDIC pode funcionar como técnica que ajuda a promover a aprendizagem dos estudantes, elas são aliadas ao fazer docente, já que os estudantes estão cada vez mais conectados, compartilhando informações, postagens, vídeos, fotos através da rede web. Com a pandemia, o papel do professor tem-se ressignificado em ambientes virtualizados. Este estudo acadêmico tem por objetivo discutir processos de ressignificação do modo de ensino por meio das tecnologias digitais de informação e comunicação nas escolas da rede, no Distrito Federal. Trata-se de uma pesquisa qualitativa, e a metodologia utilizada se respaldou em aportes teóricos e investigação prática na qual doze professores responderam a um questionário semiaberto on-line. Os resultados a que chegamos nesta pesquisa evidenciam que uma adaptação se fez necessária para os novos formatos de ensino proporcionados pela pandemia e que também falta preparo tanto dos professores, como dos estudantes para integrar com eficiência as TDIC ao contexto educacional. Consequentemente, é considerável o impacto da utilização de tecnologias digitais no ensino de línguas no cenário atual da educação.

Palavras-chave: Ressignificação; TDIC; Pandemia; Ensino.

\footnotetext{
${ }^{1}$ Mestranda do Programa de Pós Graduação em Linguística Aplicada (PGLA-UnB), Licenciada em Letras espanhol pelo Instituto Federal de Ciência, Educação e Tecnologia de Brasília e Licenciada em Letras português e inglês e respectivas literaturas pela Faculdade Evangélica; Brasília-DF, Brasil; E-mail: jessicamaryrosario@hotmail.com Lattes: http://lattes.cnpq.br/4458700916399960 ORCID: https://orcid.org/0000-0003-2853-6926

${ }^{2}$ Pós-doutora em Formação Inicial de Professores de Inglês pela Universidade Federal de Tocantins; Pósdoutora em Formação de Professores e Tecnologias (UFMG); Doutora em Linguagem e Educação (USP); Mestre em Linguística Aplicada (UNICAMP); Professora da licenciatura e bacharelado do Departamento de Ensino de Línguas e Tradução L. E. T.; Professora e Orientadora do Programa de Pós Graduação em Linguística Aplicada (PGLA-UnB); Brasília- DF, Brasil; E-mail: anafajardo@unb.br Lattes: http://lattes.cnpq.br/2069631468037931 ORCID: https://orcid.org/0000-0002-7239-5668
}

Revista Devir Educação, Lavras-MG. Edição Especial, p.29-52, Set./2021. 


\begin{abstract}
The pandemic generated by Covid-19 showed the importance of the insertion of Digital Technologies of Information and Communication (DTIC) in the educational scope, the formation of teachers requires more and more preparation for an effective teaching work. The Common National Base for the Initial Training of Basic Education Teachers (CNB-Training) in line with the Common National Curriculum Base (CNCB) recognizes the need to pedagogically employ digital innovations and languages in teaching. The use of DTIC can work as a technique that helps to promote the learning of students, they are allies in teaching, since students are increasingly connected, sharing information, posts, videos, photos through the web. With the pandemic, the role of the teacher has been redefined in virtualized environments. This academic study discusses processes of redefinition the teaching method through digital technologies of information and communication during the pandemic in the schools of the network, in the Federal District. It is a qualitative research and the methodology used was supported by theoretical contributions and practical investigation in which twelve teachers answered a semi-open questionnaire online. The results we reached in this research show that an adaptation was necessary for the new teaching formats provided by the pandemic and that there is also a lack of preparation for both teachers and students to efficiently integrate DICT into the educational context. Consequently, the impact of the use is considerable of digital technologies in the teaching of languages in the current scenario of education.
\end{abstract}

Keywords: Redefinition; DTIC; Pandemic; Teaching.

\title{
Resumen
}

La pandemia generada por la Covid-19 mostró la importancia de la inserción de las Tecnologías Digitales de Información y Comunicación (TDIC) en el ámbito educativo, la formación de docentes requiere, por lo tanto, cada vez más preparación para una labor docente eficaz. La Base Nacional Común para la Formación Inicial de Docentes de Educación Básica (BNC-Formación) en consonancia con la Base Nacional Común Curricular (BNCC) reconoce la necesidad de emplear pedagógicamente las innovaciones y los lenguajes digitales en la enseñanza. El uso de las TDIC puede funcionar como una técnica que ayuda a promover el aprendizaje de los estudiantes, ellas se alían al hacer docente, ya que los estudiantes están cada vez más conectados, compartiendo información, publicaciones, videos, fotos a través de la red web. Con la pandemia, se ha reformulado la función del docente en ambientes virtuales. Este estudio académico tiene como objetivo discutir los procesos de redefinición del método de enseñanza a través de las tecnologías digitales de información y comunicación durante la pandemia en las escuelas de la red, en el Distrito Federal. Trata-se de una investigación cualitativa y la metodología se respaldó en contribuciones teóricas e investigación práctica en la que doce profesores respondieron a un cuestionario semiabierto en línea. Los resultados que alcanzamos en esta investigación muestran que se hizo necesaria una adaptación a los nuevos formatos de enseñanza proporcionados por la pandemia y que también falta preparación tanto de docentes, como de estudiantes para integrar las TDIC con eficacia al contexto educacional. Consecuentemente, es considerable el impacto del uso de las tecnologías digitales en la enseñanza de lenguas en el escenario actual de la educación.

Palabras-clave: Redefinición; TDIC; Pandemia; Enseñanza.

Revista Devir Educação, Lavras-MG. Edição Especial, p.29-52, Set./2021. 


\section{Introdução}

A pandemia provocada pelo novo vírus, SARS-CoV-2, conhecido como coronavírus gerou inquietações, transformações e adaptações em nível mundial no ano de 2020. Com o isolamento social, a pandemia fez surgir um desequilíbrio na economia, ocasionando o fechamento de muitas empresas. Houve aumento de preocupações em relação à saúde, medo, insegurança e uma série de consequências previstas e não previstas, positivas e também negativas que ainda incidem na sociedade como um todo.

Em meio a esse cenário distinto do mundo pós chegada da Covid-19, o uso de Tecnologias Digitais de Informação e Comunicação (doravante TDIC) se intensificou no cotidiano de muitas pessoas, seja em casa ou no trabalho com a implantação do home office e nas aulas que antes eram na modalidade presencial e passaram a ocorrer de maneira remota. No entanto, já fazia um tempo que muitos pesquisadores incentivavam a inserção e o uso de ferramentas tecnológicas para um ensino mais eficaz dialogado às linguagens digitais e às novas mídias (LEFFA, 2001; ROJO; MOURA, 2012; DUDENEY; HOCKLY; PEGRUM, 2016; MENEZES, 2011; NASCIMENTO; SANTOS; SILVEIRA, 2019).

Seguindo esta perspectiva, já em 2001, Leffa argumentava usando o termo novas tecnologias, afirmando que estas "[...] introduzem mudanças que afetam a comunicação e nos obrigam a reconsiderar o que já parecia estar estabelecido" (LEFFA, 2001, p.4). Referindo-se às novas ferramentas digitais, os autores Dudney, Hockly e Pegrum acreditam que "há de chegar o dia em que nossas ferramentas estarão tão entremeadas em nossa linguagem cotidiana e em nossas práticas de letramento que quase não nos daremos mais conta delas" (DUDENEY; HOCKLY; PEGRUM, 2016, p.17). Consoante a isso, Menezes já criticava o ritmo lento em sala de aula, enquanto fora da sala de aula os alunos utilizam as novas tecnologias (MENEZES, 2011, p.279-280). Nascimento, Santos e Silveira chegam a questionar "o quanto essas novas práticas cotidianas de fora do ambiente escolar têm (ou não) adentrado as escolas" (NASCIMENTO; SANTOS; SILVEIRA, 2019, p.52) e chegam à conclusão de que, por vezes, elas são vistas como alheias à sala de aula. 


\section{OO DEVIR EDUCAÇÃO}

ISSN: 2526-849X

Com a era digital e a globalização, a sociedade está imersa em um novo ethos $^{3}$ (NASCIMENTO; SANTOS; SILVEIRA, 2019). Além disso, esses tempos críticos que vivenciamos desafiam professores e estudantes em um mundo que está se ressignificando, suscitando novas maneiras de ensinar e de aprender.

A realidade em que se encontra a educação, hoje, instiga professores a se reinventarem em uma transição que parte do tradicional ensino presencial para o ambiente de aprendizagem virtual (AVA), fazendo estudantes se adequarem a novos formatos de ensino, quer com aulas síncronas e assíncronas quer com aulas híbridas. Contudo, o acesso às tecnologias ainda é desigual e vários fatores têm inviabilizado o efetivo trabalho dos professores. Por outro lado, partimos do pressuposto de que mudanças positivas estão vindo à tona e vislumbram uma ressignificação para o ensino de línguas.

Pesquisas sobre o ensino integrado ao uso de tecnologias digitais no contexto pandêmico são muito relevantes, em especial, neste estudo, abordaremos a temática tendo como foco um escopo de 12 professores de línguas atuantes nesses tempos de pandemia.

O ensino, impulsionado pelo contexto pandêmico, suscitou novas formações docentes, advindas de cursos de aperfeiçoamento e treinamentos com o fim de capacitar professores para o trabalho com o ensino remoto, o ensino híbrido e o ensino a distância. Além disso houve mudanças que afetam o ensino sob um novo panorama. Será que elas podem trazer ressignificações ao ensino de línguas? Pensando sobre essa questão, este artigo tem por objetivo discutir processos de ressignificação do modo de ensino por meio das tecnologias digitais de informação e comunicação durante a pandemia nas escolas da rede, no Distrito Federal. Dividimos esses processos em três fases: O trabalho docente com as TDIC no ensino de línguas no início da pandemia; o trabalho docente com as TDIC no ensino de línguas durante a pandemia e tendências do trabalho docente com as TDIC no ensino de línguas (vislumbrando as aulas pós pandemia).

Trata-se de uma pesquisa de abordagem qualitativa (MORAES, 1999). A metodologia empregada neste estudo acadêmico foi subsidiada por aportes teóricos e investigação prática. A coleta de dados foi realizada no período de outubro a novembro de 2020 , por meio de questionários semiabertos que foram respondidos por professores de línguas (dentre participantes da pesquisa havia professores de português, inglês e espanhol), os quais foram

\footnotetext{
${ }^{3}$ Ethos é uma palavra com origem grega, que significa "caráter moral". É usada para descrever o conjunto de hábitos ou crenças que definem uma comunidade ou nação (Disponível em: <https://www.significados.com.br/ethos/>. Acesso em: 29 maio 2020).
} 
selecionados conforme o seguinte critério: ser professor de línguas em exercício nesses tempos de pandemia. Conseguimos obter uma amostra diversificada, com profissionais da rede pública e também da rede particular, desde docentes que atuam na educação básica até os que atuam no ensino superior, totalizando um grupo de 12 professores. Dentre esses, três professores foram selecionados e participaram de uma segunda parte da pesquisa que consistiu em responder de maneira escrita, via WhatsApp, a uma pergunta aberta; nessa amostra, optamos, por focalizar dois professores veteranos e uma professora recém-formada, a fim de obtermos dados sobre essa nova ressignificação do ensino.

A análise de conteúdo foi a estratégia de análise selecionada. Os dados dessa pesquisa foram gerados a partir das respostas dos participantes aos questionários e às perguntas aplicadas. A análise de conteúdo, conforme argumenta Moraes, conduz a “[...] descrições sistemáticas, qualitativas ou quantitativas, ajuda a reinterpretar as mensagens e a atingir uma compreensão de seus significados em um nível que vai mais além de uma leitura comum" (MORAES, 1999, p.2).

A escrita deste artigo se estrutura em mais três partes após essa introdução. Na primeira parte, abordaremos a base teórica da pesquisa. Na segunda, discutiremos, por meio dos dados gerados e das percepções de professores de línguas, os processos de ressignificação do ensino a partir do uso de TDIC nesse contexto pandêmico, englobando os impactos positivos e negativos. Por fim, apresentaremos algumas considerações finais deste trabalho.

\section{Referencial teórico}

A utilização de TDIC no âmbito educacional nunca foi tão necessária como está sendo agora, nesse contexto pandêmico. Com a disseminação da covid-19, vários professores acostumados ao ensino presencial e sem experiência com a Educação a Distância (EAD), tiveram que se adaptar a novos formatos de ensino como o ensino híbrido e o Ensino Remoto Emergencial (ERE) ${ }^{4}$.

\footnotetext{
${ }^{4}$ Entendemos por meio da resolução do Conselho Nacional da Educação (CNE) que o ensino emergencial remoto pode ser mediado pelo uso de recursos tecnológicos e digitais ou não, uma vez que há acesso desigual a tecnologias e casos de estudantes que não dispõem dos recursos necessários para as aulas, portanto, presuma-se que recebam da instituição escolar material impresso para realizar
} 
Dentro desse novo contexto sócio-histórico entrou em cena o termo ressignificar ${ }^{5}$. A ressignificação nos permite transformar crises e inquietações em aprendizados que podem trazer, portanto, melhorias (LEFFA, 2001; KUMARAVADIVELU, 2012). Assim, ressignificar não é apenas atribuir um novo significado a algo. Afinal, é preciso, nesse processo, transformar pensamentos, mudar escolhas, dar novos sentidos, saber lidar com o diferente. É tempo de refletir sobre os saberes, duvidar de certezas tão incrustadas para encontrar saídas. Estamos vivenciando um tempo de ruptura epistêmica em que reorganizar e reconceituar sistemas de conhecimento se faz necessário. De uma maneira geral, são os desafios que nos possibilitam ressignificar.

Antes da pandemia, Leffa (2001) publicou um artigo intitulado "A linguística aplicada e seu compromisso com a sociedade" em que ele já considerava a tendência de uma educação redefinida. Ele constatou que o mundo caminhava para a implementação do ensino híbrido, uma espécie de integração do ensino presencial e o ensino a distância por meio de aulas síncronas e/ou assíncronas.

\begin{abstract}
Estamos numa época em que podemos, com certa facilidade, fundir proximidade com distância; eu posso estar aqui e em vários outros lugares ao mesmo tempo, não só me replicando para ser visto e ouvido, de modo passivo, mas também para ver e ouvir, de modo ativo, interagindo com as pessoas - não só de maneira síncrona mas também assíncrona, permitindo que a interação ocorra em diferentes lugares e horários. Essa fusão do presencial com o distante possibilitou algo que se convencionou chamar de Educação a distância e que é vista por alguns como uma substituição do ensino presencial. Acho que o ensino não deve ser apenas presencial nem apenas a distância, mas dos dois modos (LEFFA, 2001, p.12).
\end{abstract}

Esse ensino se torna cada vez mais viável com as tecnologias digitais atuais. A difusão e a distribuição do conhecimento entre as pessoas estão formando uma imensa rede virtual, construída de maneira coletiva e colaborativa. Leffa constatou que a sociedade entraria em um tempo em que todo conhecimento seria compartilhado (LEFFA, 2001, p.8). Nunca antes estivemos tão interconectados como nos tempos atuais. Em pesquisa recente, Leffa (2020) tem focalizado em estudos de gamificação como recurso de aprendizagem.

as atividades das aulas. Para mais informações sobre essa resolução, acesse o seguinte link: <https://drive.google.com/file/d/1jrZLd8aI5VQLgutfNwTR3ZW3BqFsAzE8/view〉.

${ }^{5}$ Ressignificar é atribuir um novo significado a; dar um sentido diferente a alguma coisa; redefinir. (Disponível em: <https://www.dicio.com.br/ressignificar/>. Acesso em: 29 set. 2020). 
A Base Nacional Comum Curricular (BNCC) é um documento oficial que regulamenta acerca das aprendizagens essenciais que os estudantes da educação básica precisam desenvolver. O documento adotou a terminologia teórica TDIC (Tecnologias Digitais de Informação e Comunicação) em vez de TIC (Tecnologia de Informação e Comunicação) abarcando, assim, as novas abordagens que integram a cultura digital e o ensino. A BNCC também discorre sobre a necessidade de o ensino de línguas abarcar os multiletramentos e os novos letramentos, reconhecendo a importância de utilizar mídias e ferramentas digitais de maneira crítica (BRASIL, 2018).

Após a implementação da BNCC nas escolas de todo o país com vistas à universalização da educação básica, o Ministério da Educação entregou para o Conselho Nacional da Educação uma proposta chamada Base Nacional Comum para a Formação Inicial de Professores de Educação Básica (BNC- Formação) ${ }^{6}$. O documento traz três eixos que compõem as competências profissionais a serem trabalhadas na formação inicial e na formação continuada dos docentes de todo o Brasil. Dentre as competências exigidas, destacamos a competência de número cinco, a qual registra que compete ao professor:

Compreender, utilizar e criar tecnologias digitais de informação e comunicação de forma crítica, significativa, reflexiva e ética nas diversas práticas docentes, como recurso pedagógico e como ferramenta de formação, para comunicar, acessar e disseminar informações, produzir conhecimentos, resolver problemas e potencializar as aprendizagens (BRASIL, 2019, p. 13, grifo nosso).

Mesmo em meio ao contexto atual de reformulação curricular das escolas, a BNCFormação foi proposta. Contreras registra que “[...] são cada vez maiores as funções atribuídas ao ensino, pretendendo-se que os docentes atendam as esferas da educação cada vez mais difusas e ambíguas" (CONTRERAS, 2002, p.151). Na visão de Saviani, é preciso que haja uma boa formação docente que preze pelas qualidades que constituem a formação de um bom professor (SAVIANI, 2011, p.16). No entanto, refletindo sobre essas questões

\footnotetext{
${ }^{6}$ Para mais informações acerca da Base Nacional Comum para a Formação Inicial de Professores de Educação Básica, acesse o link:

〈http://portal.mec.gov.br/docman/dezembro-2019-pdf/135951-rcp002-19/file〉 .Acesso em: 29 maio 2020 .
} 
apontadas pelos autores e sobre o que está posto na BNC- Formação, percebemos que nem todos os professores dispõem do necessário para a efetivo trabalho docente.

Em maio de 2020, quando o Brasil já enfrentava o contexto pandêmico, um parecer acerca da Base Nacional Comum de Formação Continuada (BNC- Formação Continuada) ${ }^{7}$ foi publicado. O documento também versa sobre a necessidade de docentes utilizarem novas metodologias, dentre elas as que abranjam a utilização das TDIC para o ensino, seja ele semipresencial, híbrido ou a distância. Logo, é indispensável aprender novas abordagens educacionais, em um mundo que se ressignifica e requer de professores e alunos novos aprendizados (BRASIL, 2020, p.5).

Com a pandemia, voltou à tona um discurso de que em breve não haverá mais aulas presenciais, elas serão substituídas pelo ensino mediado pelas tecnologias digitais. Essa afirmação é problemática, apesar de que, realmente, há um novo significado para o uso das ferramentas digitais no ensino de línguas, uma vez que elas contribuem nesse contexto vigente, oferecendo novas possibilidades, porém, a exclusão digital ainda é um sério problema que afeta o ensino, visto que nem todos dispõem de recursos para as aulas.

Há um novo cenário econômico crítico proveniente da crise no comércio; o isolamento tem afetado a saúde mental de muitas pessoas e, em meio a tudo isso, a crise na saúde nos obriga a seguir um rígido protocolo para manter o convívio entre os indivíduos, tudo isso impacta o ensino de línguas de alguma maneira. Esse período de pandemia tem sido muito difícil e caótico para docentes tanto da rede pública, como da rede privada que estão se desdobrando para dar conta das diversas demandas.

As práticas digitais estão em constante transformação, e essa fusão de mudanças produzidas tem impactado os usos da língua. Nos dias de hoje, a comunicação por meios digitais foi intensificada. Portanto a língua, por ser viva e dinâmica, se ambienta também no mundo digital, transformando a nossa relação com o conhecimento e com o mundo. Mediante a multimodalidade, os recursos que integram o texto se potencializaram e se expandiram.

\footnotetext{
${ }^{7}$ Para saber mais informações sobre esse parecer da Base Nacional Comum de Formação Continuada, acesse $\quad 0$ seguinte link: 〈https://formacaoprofessordotcom.files.wordpress.com/2020/05/parecer fcd cne maio 2020.pdf $>$. Acesso em: 12 set. 2020.
}

Revista Devir Educação, Lavras-MG. Edição Especial, p.29-52, Set./2021. 
A maneira como lemos o mundo também tem ganhado novos significados, um novo ethos. Por meio da diversidade de recursos da web $2.0^{8}$, hoje em dia é possível criar conteúdo digital, fazer edição de slides de maneira colaborativa, contribuir em redes sociais coletivas, realizar as aulas síncronas através de plataformas on-line, algo que não era possível com a antiga rede web (DUDENEY; HOCKLY; PEGRUM, 2016; ROJO; MOURA, 2012).

Com o advento das tecnologias digitais, temos mudanças que afetam a comunicação. Novos desafios são impostos ao ambiente educacional e à sociedade como um todo, exigindo, deste modo, que os professores se apropriem de multiletramentos e de novos letramentos, em especial, os letramentos digitais ${ }^{9}$ tão importantes nesses tempos contemporâneos em que as fusões estão sendo favorecidas pela globalização. Ademais, compete ao educador, ampliar o repertório cultural dos estudantes (LEFFA, 2001; ROJO; MOURA, 2012).

Com a tecnologia existente atualmente, é possível que o professor, de certa forma, adapte as atividades ao meio virtual. No entanto, cabe ao professor, escolher criticamente as tecnologias digitais pertinentes para desenvolver suas aulas. Afinal, só incluir o uso de TDIC não é suficiente se a aula for conduzida seguindo os moldes tradicionais de centralidade na gramática, repetição e ênfase no conteúdo que, portanto, não incorporam as novas abordagens e metodologias de ensino.

A complexidade presente no mundo de hoje exige do professor uma formação mais abrangente que abarque a responsabilidade de ser inovador, comprometido, organizado, sabendo estabelecer um ambiente de aprendizagem prazeroso que se conecta à realidade dos estudantes. Menezes (2011) utiliza a metáfora do Rizoma proveniente dos filósofos franceses Deleuze e Guatari, definindo esse mundo de hoje como um mundo "rizomático", um mundo múltiplo com suas teias de comunicação em que só os métodos e livros didáticos não bastam.

Nós vivemos em um mundo complexo, globalizado. Múltiplo. E é um mundo marcado por fluxos de todos os tipos, fluxos de pessoas, acima de tudo fluxo de capital, fluxos de artigos, fluxo de informações e esses fluxos acontecem com uma rapidez enorme. E isso tudo parece acontecer fora da sala de aula, mas dentro da sala de aula parece que ainda estamos naquele ritmo antigo, bem devagar; no ensino da língua materna, por

\footnotetext{
8 Para mais informações sobre a web 2.0 acesse o link: <https://brasilescola.uol.com.br/informatica/web-20.htm>. Acesso em: 6 ago. 2020

9 Letramentos digitais: habilidades individuais e sociais necessárias para interpretar, administrar, compartilhar e criar sentido eficazmente no âmbito crescente dos canais de comunicação digital (DUDENEY; HOCKLY; PEGRUM, 2016, p.17).
} 
exemplo, existe ainda o debate de como é que o professor deve lidar com os meios de comunicação que o aluno está acostumado a usar fora da sala de aula, a internet especialmente, videogames, jogos de computador. Qual a relação entre tudo isso e a sala de aula? (MENEZES, 2011, p. 279-280)

Diante desse mundo múltiplo, precisamos de uma redefinição para o trabalho em sala de aula, seja ela virtual ou presencial. Ainda que o acesso à leitura tenha se ampliado, muitos estudantes se perdem em meio ao fluxo de informações, à pluralidade de ideias, conceitos e textos diversos. Os educandos não chegam à sala de aula vazios, eles trazem uma bagagem sociocultural e um prévio conhecimento de mundo. O papel do professor como mediador da aprendizagem é conduzir o estudante nesse processo complexo de orientação e colaboração, sem perder de vista que o educando tenha a função ativa na construção do conhecimento.

Pensando nesse contexto atual que vivenciamos e no impacto do uso das novas tecnologias redefinindo a formação de professores, é válido refletirmos sobre os efeitos positivos e negativos sentidos pelos professores/as em relação a essas questões. Afinal as tecnologias digitais são aliadas no fazer docente, estão presentes no cotidiano de muitos estudantes que, cada vez mais conectados, compartilham informações, postagens, vídeos, fotos através da rede web. Logo, as TDIC não podem ficar alheias ao ensino de línguas.

\section{2- A ressignificação do ensino de línguas a partir do uso intensivo das TDIC em tempos de pandemia: análise de dados}

Como vimos anteriormente, o objetivo desta pesquisa é discutir processos de ressignificação do modo de ensino por meio das tecnologias digitais de informação e comunicação nas escolas da rede. Essa investigação é contextualizada tendo em vista a educação de Brasília nos tempos atuais. Algumas escolas voltaram a ter aulas presenciais, seguindo um rígido protocolo, há professores que atuam na $\mathrm{EAD}$, os que trabalham no ERE e os que gradualmente retornam ao ensino presencial, atuando no que se denominou como ensino híbrido. Participaram da pesquisa 12 professores de línguas de diferentes domínios: quatro atuam no ensino fundamental, três lecionam no ensino médio, dois trabalham na modalidade Educação de Jovens e Adultos (EJA), dois lecionam no ensino superior e um atua 
na educação infantil. Com o fim de preservar a identidade dos participantes, eles serão chamados pelo pseudônimo previamente escolhido por eles na pesquisa, como podemos ver no quadro a seguir:

Tabela 1 - Quadro de participantes da pesquisa

\begin{tabular}{|c|c|c|c|c|}
\hline Docentes & Leciona: & $\begin{array}{l}\text { Escola } \\
\text { Pública }\end{array}$ & $\begin{array}{l}\text { Escola } \\
\text { particular }\end{array}$ & Atua no: \\
\hline 1- Quitéria & Inglês & $\mathrm{X}$ & & Ensino Médio \\
\hline 2- Wesley Alves & Espanhol & & $\mathrm{X}$ & Ensino Médio \\
\hline 3- Raquel & Português & $\mathrm{X}$ & & $\begin{array}{l}\text { Ensino } \\
\text { Fundamental }\end{array}$ \\
\hline 4- Resistência & Português & $\mathrm{X}$ & & EJA \\
\hline 5- Florinda & Inglês & & $\mathrm{X}$ & $\begin{array}{l}\text { Ensino } \\
\text { Fundamental }\end{array}$ \\
\hline $\begin{array}{l}\text { 6- Professora de } \\
\text { inglês }\end{array}$ & Inglês & & $\mathrm{X}$ & $\begin{array}{l}\text { Ensino } \\
\text { Fundamental }\end{array}$ \\
\hline 7- TK & Espanhol & & $\mathrm{X}$ & $\begin{array}{l}\text { Ensino } \\
\text { Fundamental }\end{array}$ \\
\hline 8- Zoe & Inglês & & $\mathrm{X}$ & $\begin{array}{l}\text { Educação } \\
\text { Infantil }\end{array}$ \\
\hline 9- Professor Zion & Inglês & $\mathrm{X}$ & & EJA \\
\hline 10-Caetano & Espanhol & $\mathrm{X}$ & & Ensino Médio \\
\hline 11- João & Espanhol & $\mathrm{X}$ & & Ensino Superior \\
\hline 12-Leah & Espanhol & $\mathrm{X}$ & & Ensino Superior \\
\hline
\end{tabular}

Revista Devir Educação, Lavras-MG. Edição Especial, p.29-52, Set./2021. 
Um questionário on-line (formulário google docs) formulado com 16 questões, sendo oito questões de múltipla escolha e oito discursivas, foi aplicado aos professores de línguas. Uma segunda parte da investigação foi realizada com uma professora veterana (Resistência), uma professora recém-formada (TK) e um professor veterano (Wesley Alves). A análise está organizada em três fases. Nelas, serão abordados os pontos positivos e negativos do trabalho docente no início da pandemia, durante a pandemia e as tendências vislumbradas pós pandemia.

A primeira questão do questionário foi: o acesso à internet de boa conexão é um dos fatores que viabilizam o trabalho do professor no ERE. Como está o seu acesso à internet? Onze professores responderam marcando a opção "tenho acesso à internet banda larga de alta qualidade". Já na segunda questão, a pergunta foi: quais são os dispositivos que mais utiliza em suas aulas? Os professores apontaram os itens: "notebook" e "smartphone", como os mais utilizados. Dudney, Hockly e Pegrum (2016) abordam acerca da proliferação dos dispositivos móveis como uma forte tendência de apoio ao ensino de línguas. Esse resultado endossa tal perspectiva, já que os dados nos levam a entender que esses professores têm usado mais os dispositivos móveis. O uso concomitante do celular e do notebook oferece flexibilidade e maior comunicação para o preparo e a execução das aulas.

\subsection{Fase 1: o trabalho docente com as TDIC no ensino de línguas no início da pandemia}

O início da pandemia exigiu uma ressignificação do ensino com adaptação em relação ao tempo, a metodologias, à participação dos estudantes nas aulas, à utilização de plataformas para mediar as aulas, além de vídeos, tutoriais, cursos variados para treinamento e capacitação de professores. E toda essa cobrança de preparo e adaptação impactou a própria formação docente: eles sentiram que estavam despreparados.

Visando a definir o trabalho docente no início da pandemia, a terceira questão trouxe alguns dados. A pergunta foi: como foi o seu trabalho docente mediado pelo uso das novas tecnologias no início da pandemia? "Desafiador" e "difícil" foram os adjetivos mais utilizados pelos professores que responderam. Realmente, esse novo tipo de ensino exigiu de professores um processo de adaptação, tanto para o uso de TDIC, como para o ensino em si, que foi repensado e reconfigurado nos moldes do ERE. Destacamos algumas respostas:

Revista Devir Educação, Lavras-MG. Edição Especial, p.29-52, Set./2021. 


\section{OO DEVIR EDUCAÇÃO \\ ISSN: 2526-849X}

Raquel: muito difícil, demorado, maior disposição de tempo para planejamento e criação de atividades. Para criar uma atividade para o ensino remoto, por exemplo: leva o dobro do tempo ou mais que para planejar e criar.

Resistência: desafiador... mas surpreendente pq [sic] apesar de poucos alunos participando... os que entravam participaram efetivamente.

Zoe: utilizamos diversas plataformas para mediar aulas síncronas e assíncronas. Tivemos que aprender muitas coisas (Fonte: Questionário das autoras, 2020).

Com a mudança de concepção de internet oriunda da web 2.0, não temos apenas uma mera interação nas aulas, mas a oportunidade de produção coletiva do conhecimento (ROJO; MOURA, 2012). Esse caso específico, da Professora Resistência é resultante das novas maneiras de interagir em aulas virtuais síncronas, sem a presença física do professor e dos estudantes. Se comparamos com a aula presencial em que, no geral, há uma espera para se ter o turno de fala, já que o entendimento ficaria comprometido com tanto ruído de várias vozes falando ao mesmo tempo, nas aulas em ambientes virtualizados, as interações se transformam, são colaborativas, estudantes dizem o que pensam no chat de forma simultânea, algo que não acontecia na antiga rede web.

A pergunta de número 4 foi: como você se preparou para utilizar as ferramentas digitais no início das aulas no ensino remoto? Florinda afirma que se preparou "com estudos e reflexões sobre a pedagogia dos multiletramentos" (Fonte: Questionário das autoras, 2020). A educação multiletrada traz contribuições à formação docente, ampliando a visão, não só em relação à importância do uso das tecnologias digitais na educação atual, mas em relação ao multiculturalismo e à multimodalidade dos textos, que por sua vez ressignificam os modos de ensinar e de aprender (ROJO; MOURA, 2012). Duas docentes (Raquel e Resistência) contam que fizeram cursos ofertados pela Secretaria de Educação, os outros docentes comentaram busca por vídeos, lives, cursos de capacitação, treinamentos, portanto, em geral, é perceptível que houve busca de aprimoramento e familiarização com as TDIC.

A questão 5 foi: como você se sentiu em relação ao ensino mediado pelas tecnologias digitais? "Sozinho", "desafiado", "desnorteado", "impotente" e "inseguro", esses foram alguns dos adjetivos usados para descrever o sentimento desses professores no início da pandemia. As dificuldades foram várias: dificuldades na interação com os alunos, dificuldades decorrentes da falta de conhecimento de uso das ferramentas digitais, sobrecarga 
de atividades, insegurança gerada pela ruptura do presencial para o virtual sem muito preparo. Podemos ver algumas respostas a seguir:

Professora de inglês: menos crítica com as plataformas tecnológicas e otimista com as novas possibilidades.

TK: foi difícil, porque foi uma modalidade que tivemos que acatar e realizar sem muito preparo. Mas com a prática, fomos aprendendo e os alunos também. Posso dizer que, com o passar do tempo, eu tomei gosto por dar aulas utilizando totalmente as tecnologias digitais. Gostei da praticidade e da inovação.

Zoe: me senti sozinha, era estranho ver os alunos pela tela e não pessoalmente. Tinha medo, me sentia julgada e tive ansiedade, pois era muito mais complicado planejar as aulas.

Leah: já possuía experiência prévia em Ead [sic], mas considero que o ensino remoto emergencial promoveu desafios diferentes (Fonte: Questionário das autoras, 2020).

A angústia de não terem passado por uma boa preparação antes é quase unânime entre os participantes que responderam à pesquisa, com exceção da Professora de inglês, que se sentiu otimista. A competência geral de número 8 da BNC- Formação (BRASIL, 2019, p.5) aborda sobre o autocuidado que o professor precisa ter com sua saúde física e emocional. Zoe desabafou "Me senti sozinha [...]" esse sentimento dela e de outros professores revela que, nesses tempos críticos, os docentes estão necessitando de apoio.

A formação acadêmica é um ponto importante para refletirmos sobre a ressignificação. A questão 6 registra: você considera sua formação sólida/robusta em relação ao uso das Tecnologias Digitais na educação? Busca aperfeiçoamento? Na pesquisa, sete participantes não consideram a formação deles robusta em relação ao uso de tecnologias digitais na educação. É preciso levar em conta o fato de que muitos desses professores se formaram quando ainda não tínhamos esses avanços digitais e tecnológicos, tampouco a BNCC. Wesley Alves pondera que "sempre é importante se reciclar e inovar" (Fonte: Questionário das autoras, 2020). Como aspecto positivo, foi possível constatar que os recém-formados são os que se sentem mais familiarizados com o uso das novas TDIC nas aulas. Não há dúvidas de que a BNCC vai demandar dos professores de educação básica, um aprimoramento da prática pedagógica (BRASIL, 2018).

Podemos inferir, a partir dos dados levantados, que o início da pandemia exigiu uma ressignificação do ensino com adaptação em relação a diversos aspectos como tempo, 
metodologia, entre outros. Os sentimentos gerados nos docentes em relação ao ensino mediado pelas tecnologias digitais foram mais negativos do que positivos. Muitos professores alegam que a formação acadêmica não dá conta de todas as inovações tecnológicas, sendo indispensável ao professor aprimorar seus conhecimentos.

Menezes afirma que "[...] nosso papel como professores hoje em dia não é mais transmitir conhecimento, mas ensinar maneiras novas de buscar conhecimento" (MENEZES, 2011, p.289). Também é pertinente considerar que a responsabilidade não é totalmente do professor, uma vez que não é só o docente que lidará com o uso das ferramentas tecnológicas, os estudantes também têm dificuldades em acompanhar as aulas e usar os recursos tecnológicos, como veremos no tópico a seguir.

\subsection{Fase 2: o trabalho docente com as TDIC no ensino de línguas durante a pandemia}

Nesse processo de ressignificação do ensino de línguas durante a pandemia, dados quantitativos revelaram aspectos que mais impactaram o trabalho docente. Perguntados sobre que aspecto foi mais impactado no trabalho com o ensino remoto emergencial, 11 professores acreditam que a qualidade das interações com os alunos foi a mais afetada, sendo que cinco desses 11 professores também apontaram as metodologias de aprendizagem como aspecto mais afetado.

A BNC- Formação Continuada pontua que "[...] é exigido do Professor sólido conhecimento dos saberes constituídos, das metodologias de ensino, dos processos de aprendizagem e da produção cultural local e global, objetivando propiciar o pleno desenvolvimento dos educandos (BRASIL, 2020, p.1). A questão chave é que o contexto pandêmico trouxe novos desafios e fez com que os docentes buscassem metodologias diferenciadas para desenvolver as aulas no ERE.

Buscando conhecer o tempo de dedicação desses professores ao trabalho no contexto pandêmico, a questão 8 expressa: as tecnologias digitais impactam a educação na gestão de tempo e espaço. Como foi esse impacto em relação à quantidade de horas de trabalho? Todos os participantes responderam que estão trabalhando mais horas, sendo que cinco deles marcaram a opção "trabalho mais horas" e sete marcaram a opção "trabalho muito mais horas" do que antes da pandemia. Esses dados alertam sobre o esgotamento de muitos 
professores em um trabalho multitarefas não só para dar conta das demandas das aulas, mas também conciliar as aulas com as outras demandas da vida, atividades domésticas, o cuidado com os filhos, dentre outras atividades cotidianas.

Saviani (2011) acredita que o ideal seria que os docentes não trabalhassem em várias escolas, mas em apenas uma e em tempo integral, para que assim houvesse tempo suficiente para a preparação das aulas e demais atividades, corroborando as respostas da pergunta 8. A gestão do tempo está sendo desafiadora para grande parte dos docentes pesquisados.

A pouca frequência dos estudantes nas aulas é algo preocupante, no que tange à questão 9: que problemas mais afetam a presença discente nas aulas? Cinco docentes responderam que cerca de $30 \%$ dos estudantes têm frequência assídua nas aulas. Em contraposição a isso, apenas um docente (Wesley Alves) respondeu que tem $100 \%$ de presença dos estudantes nas aulas. Correlacionada a essa questão, a pergunta de número 10 foi: que problemas mais afetam a presença discente nas aulas? A infrequência de estudantes já era um problema no ensino presencial e, com o ERE, o problema se agrava ainda mais, pois os recursos tecnológicos não são acessíveis a todos e são passíveis de problemas técnicos, à falta de energia, à condições adversas de tempo, que atrapalham o sinal da internet. A ausência de estudantes nas aulas dos participantes da pesquisa ocorre, principalmente, por falta de condições em casa de participar das aulas e falta de acesso à internet.

No que tange à participação dos estudantes nas aulas, houve um empate técnico dos estudantes que participam das aulas usando chat, câmera e microfone quando necessário e dos que usam apenas o microfone e o chat. Há um percentual considerável de estudantes que usam apenas o chat, além disso também foram citados os que usam o WhatsApp. Os dados gerados estão no gráfico a seguir. A BNCC discorre que "ao aproveitar o potencial de comunicação do universo digital, a escola pode instituir novos modos de promover a aprendizagem, a interação e o compartilhamento de significados entre professores e estudantes” (BRASIL, 2018, p.61). Com as aulas síncronas, há uma preocupação em relação à efetividade dessa participação. 
11- De que maneira os alunos/as participam da aula?

12 respostas

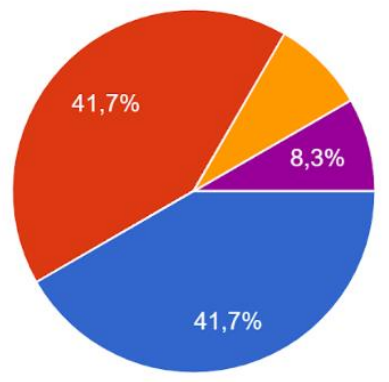

Com o chat, câmera, microfone sempre que necessário

Usam apenas o microfone e o chat

Usam apenas o chat

Nunca se manifestam nas aulas

Whatsapp

Figura 1 - Gráfico de participação dos estudantes (Fonte: Das autoras, 2020).

Há um consenso de que a interação com os alunos nesse ambiente virtualizado está sendo prejudicada. A questão 12 expressa: quais são as maiores dificuldades que você enfrenta com o uso das novas tecnologias em suas aulas? As dificuldades se diversificam, há impacto na interação com os alunos, o cansaço dos estudantes, rotina intensa e até dificuldade de acesso à internet. Essa exclusão digital é real, há alunos que não têm os recursos tecnológicos e digitais para participarem das aulas. As dificuldades apontadas pelos docentes também revelam a necessidade dos letramentos digitais nesse novo contexto de ensino. Mencionamos a seguir algumas respostas dos docentes em relação a essas dificuldades:

Wesley Alves: internet dos alunos.

Resistência: cumprir as rotinas... os estudantes vão se cansando ao longo do tempo. TK: a interação com os alunos, o fato de não poder controlar a atenção dos alunos por causa da distância. A dificuldade dos alunos em conseguir entender [sic] o processo a distância (Fonte: Questionário das autoras, 2020).

Os dados gerados mostram que existem prejuízos na interação aluno-professor nesse novo contexto virtual. Vale lembrar Menezes (2011) que sublinha o debate de como o professor deve lidar com os meios de comunicação e as ferramentas tecnológicas que o aluno está acostumado a usar fora da sala de aula. O referido autor também traz a ideia dos fluxos, a tecnologia e os fluxos de informação, fluxos diversos que pressionam a escola. No entanto, 


\section{OD DEVIR EDUCAÇÃO \\ ISSN: 2526-849X}

observamos, por meio dos dados, que ainda há problemas em relação à interação, além disso, a ausência de estudantes nas aulas parece evidenciar essa interação precária.

$\mathrm{O}$ trabalho docente com as TDIC no ensino de línguas durante a pandemia instiga professores a repensarem o ensino. Essa redefinição das aulas pode ser positiva em um ensino que cada vez mais precisa inovar. Os docentes pesquisados vislumbram tendências que abordaremos no tópico a seguir.

\subsection{Fase 3: tendências do trabalho docente com as TDIC no ensino de línguas (vislumbrando as aulas pós pandemia)}

Há um consenso dos participantes da pesquisa de que com a volta das aulas presenciais, o ensino mudará. Tendo em vista isso, a questão 13 pergunta: você acha que com o retorno das aulas presenciais sua atuação como professor mudará? De que maneira? Três professoras (Florinda, TK e Zoe) mencionaram o ensino híbrido como tendência e realidade já presente nas escolas em que trabalham, tal como apontava a previsão de Leffa (2001), ao afirmar que o ensino não seria apenas presencial e nem somente a distância, porém, uma mescla dos dois modos. Além disso, muitos mencionaram que o trabalho docente continuará tendo o apoio das tecnologias. Duas docentes (Raquel e Professora de inglês) acreditam que haverá ainda um protocolo rígido a ser seguido nas escolas, impossibilitando contato físico, trabalhos em grupo (do modo tradicional), fato que também desencadeará impacto nas avaliações de aprendizagem.

Acerca das mudanças positivas advindas do ensino remoto, os itens mais escolhidos pelos professores revelam que eles estão se engajando no uso de TDIC para as aulas on-line e aprendendo novas maneiras de ensinar. O gráfico a seguir explicita isso:

Revista Devir Educação, Lavras-MG. Edição Especial, p.29-52, Set./2021. 


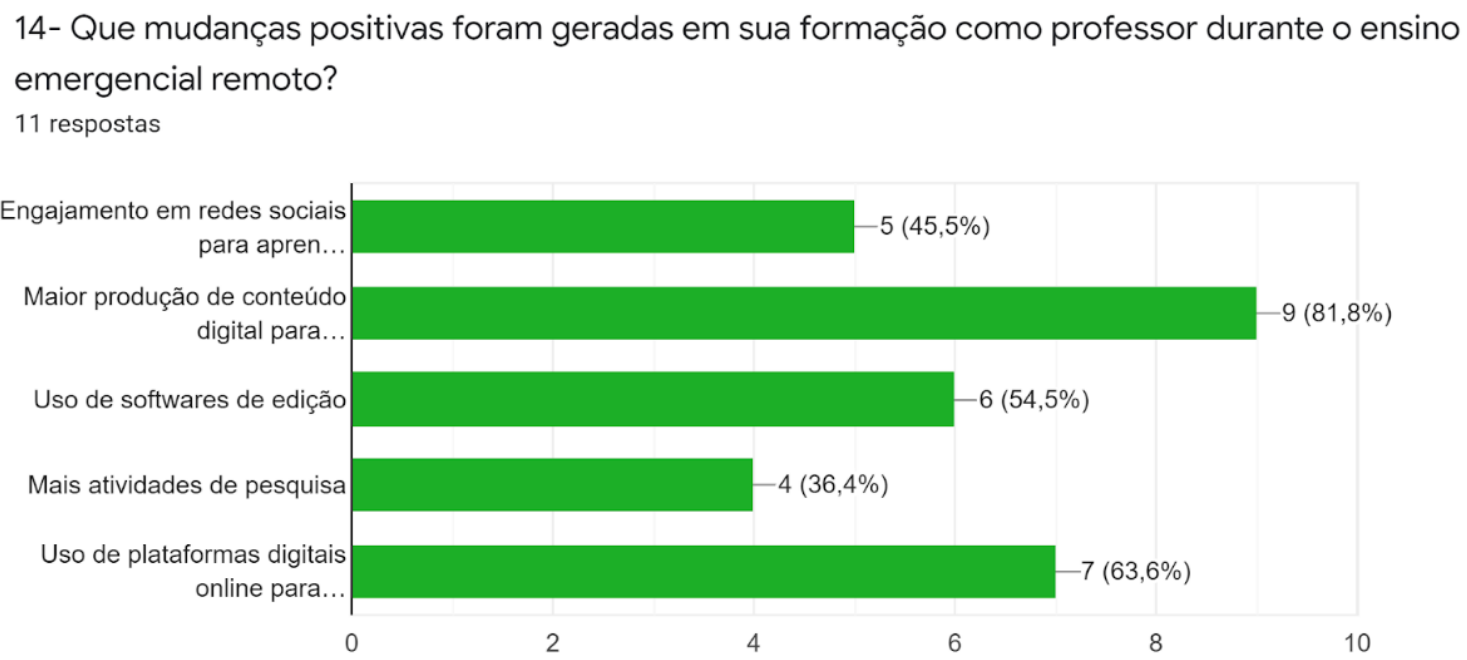

Figura 2 - Gráfico de mudanças positivas (Fonte: Das autoras, 2020).

A BNC- Formação, no eixo da prática profissional de professores, prescreve que é responsabilidade do docente "criar e saber gerir ambientes de aprendizagem" (BRASIL, 2019, p. 2), também ao mesmo tempo é exigido "planejar as ações de ensino que resultem em efetivas aprendizagens" (BRASIL, 2019, p. 2). Os participantes da pesquisa nos levam a entender, por meio dos resultados, que estão se desenvolvendo apesar das dificuldades.

Como você avalia seu trabalho? O que considera que tem sido mais desafiador no seu trabalho como docente nesse contexto atual? Metade dos professores acreditam que o trabalho deles está bom, muitos acreditam que pode melhorar. A adaptação os desafia, o uso das TDIC também, pois os recursos digitais e a internet, às vezes, falham. O professor João desabafa que seu trabalho tem sido "Muito desafiador e cansativo" (Fonte: Questionário das autoras, 2020). Os participantes da pesquisa se sentem desafiados a melhorar a sua práxis, a aprender novos métodos, a manter o aluno interessado nas aulas nesse contexto inédito, e isso os desgasta. Essas autorreflexões dos professores apontam para uma ressignificação, uma busca constante desses professores de melhorarem o ensino de línguas.

Em meio a tantas cobranças, os professores de línguas desejam receber apoio para o trabalho nesses tempos de pandemia. A questão 16 foi: que tipo de apoio você considera que seria essencial para a continuidade de seu trabalho com o ensino remoto? Eles querem apoio, seja apoio psicológico ou na formação, seja tempo para reflexão docente. Querem ajuda para conseguir assiduidade dos estudantes nas aulas, suporte da instituição de ensino em termos de estrutura, investimento em internet, aparelhos eletrônicos. Saviani nos alerta para o 
fato de que, predominantemente, em políticas públicas, há uma pauta de que devemos sempre reduzir custos, cortando investimentos (SAVIANI, 2011, p.17). Ele considera que, infelizmente, a educação não tem sido devidamente valorizada.

Ressignificar, nesse contexto pandêmico, tem sido fundamental. Três professores responderam via WhatsApp à pergunta: para você, o que significa o termo "ressignificar”? Como você enxerga a ressignificação do uso de novas tecnologias a partir de suas aulas nesses tempos de pandemia? Os participantes sentiram mudanças que fizeram surgir uma ressignificação do modo de ensino por meio do uso das tecnologias digitais; foram elas que deram suporte para que as aulas acontecessem em meio aos novos desafios do cenário da pandemia, como podemos comprovar nesse argumento da professora TK.

TK: ressignificar é dar um novo significado a algo que já existe e que já é utilizado, mas que agora pode ser utilizado dando novos significados há [sic] diferentes contextos. No nosso atual cenário, a educação precisou de apoio, e esse apoio foi proporcionado pelas novas tecnologias. Antes a educação acontecia, às vezes se utilizava aqui ou ali as TICS, mas na nova situação vigente [pandemia] onde todos foram e estão proibidos de sair de casa, as tecnologias amparam a educação, foi através da tecnologia que a educação conseguiu alcançar seus objetivos, embora com dificuldades de adaptação. As aulas na pandemia utilizando as tecnologias digitais, foram a princípio difíceis. O professor estava centrado ao quadro e apagador, ao presencial, olho no olho, a ter "quase" o total controle da sala de aula. Mas com o advindo das tecnologias, a sala de aula passou a ser virtual, o quadro passou a ser o PowerPoint e nos víamos por uma telinha (quando nossos amados alunos a ligavam). A questão é que a tecnologia ajudou porque nos proporcionou conhecimentos novos, facilitou para que o ano não fosse perdido e para que os alunos não perdessem conteúdo. Por isso, digo que nós professores ressigficamos [sic] nossa sala de aula, nossa prática, tivemos que aprender a mexer em muitas plataformas novas, mas que nos ajudaram no exercício da docência. Tivemos que mudar nossa postura, controlar o incontrolável para que a aula fosse produtiva e eficaz. Ressignificar tem haver [sic] com adaptação é assim que vejo e vi minhas práticas no cenário de pandemia (Fonte: Questionário das autoras, 2020).

Uma ressignificação da postura de docentes como TK se fez necessária, horizontes se ampliaram e uma nova visão acompanha esses professores que agora se veem mais experientes com as vivências proporcionadas nesse período tão difícil.

Nessa última fase, analisamos efeitos dos processos de ressignificação no ensino de línguas com as TDIC, vislumbrando tendências pós pandemia. Não se pode negar que professores que resistiam ao uso das tecnologias digitais nas aulas, por terem obtido um certo nível de familiarização com os recursos digitais e tecnológicos continuarão a utilizá-los. 
Portanto, há uma forte tendência de que os professores continuem a produzir materiais digitais para as aulas e utilizem as diversas ferramentas on-line.

Os aspectos que desafiam os participantes para uma nova projeção de ensino são variados e vão desde a adaptação para atuar no ensino híbrido até a busca pelo conhecimento, não só para melhorar o planejamento das aulas, mas para o uso mais eficaz das ferramentas digitais. Para realizar tudo isso e ainda despertar o interesse dos estudantes nessa nova conjuntura, contudo, é necessário apoio. Os processos de ressignificação do modo de ensino vivenciados por esses professores de línguas do DF vislumbram um ensino mais dialogado com as TDIC e mais conectado ao perfil do estudante contemporâneo. Novas maneiras de aprender e ensinar emergem, ressignificando a práxis docente para além da sala de aula física presencial tradicional.

\section{Algumas considerações finais}

É inegável que muitas pesquisas já retratavam a importância da inserção de novas tecnologias na formação de professores. Nos tempos de hoje com a pandemia, essa inserção se tornou imprescindível. Diante dessa realidade, buscamos discutir processos de ressignificação do modo de ensino por meio das novas tecnologias digitais de informação e comunicação nas escolas da rede, no Distrito Federal. Para a análise dos dados referente ao tema, tivemos 12 questionários respondidos pelos professores de línguas e uma questão que foi respondida via WhatsApp por participantes selecionados.

O trabalho docente dos participantes da pesquisa com as TDIC no ensino de línguas no início da pandemia foi difícil e desafiador. Os primeiros resultados evidenciam que houve ressignificação do ensino de línguas quanto à modalidade: ensino presencial, ensino híbrido e ensino remoto, uma adaptação se fez necessária para os novos formatos de ensino proporcionados pela pandemia, até os professores que já tinham intimidade com as tecnologias tiveram que reinventar suas aulas, utilizando dispositivos e ferramentas digitais em um contexto completamente novo. Durante a pandemia, a comunicação entre professores e alunos precisou ser remodelada, especialmente em ambientes digitais por meio de diferentes suportes e estratégias de ensino. Os professores participantes da pesquisa já lançados aos novos desafios, desabafam acerca dos problemas vivenciados com as dificuldades 
enfrentadas, expõem que foi preciso uma redefinição das aulas, e os resultados mostram que a interação com os alunos foi um dos aspectos mais comprometidos entre os que frequentam as aulas, além disso, alertam para o problema da infrequência de muitos discentes nas aulas. A formação docente foi reconfigurada para um novo panorama de educação, exigindo ainda mais habilidades. Em relação às novas projeções para o ensino, os resultados vislumbram impacto nas avaliações de aprendizagem, há uma forte tendência de que o ensino pós pandemia seja híbrido e de que os recursos digitais continuarão a ser utilizados nas aulas.

É pertinente reconhecer que ainda falta um bom preparo, tanto dos professores como dos estudantes, para integrar de maneira efetiva as TDIC nas aulas. Com base nos resultados gerados, observamos a necessidade de novas pesquisas frente a problemas, tais como: a infrequência de estudantes nas aulas e a adequação de aplicativos e ferramentas para o ensino. É considerável o impacto da utilização de ferramentas digitais no ensino de línguas no cenário atual. As TDIC desdobram novas possiblidades no processo didático pedagógico, portanto é possível afirmar que as mudanças advindas desses tempos de pandemia trouxeram novos aprendizados aos docentes e ressignificações relevantes ao ensino de línguas.

\section{REFERÊNCIAS}

BRASIL. Base Nacional Comum Curricular: Ensino Médio. Brasília: MEC/Secretaria de Educação Básica, 2018.

BRASIL. Ministério da Educação. Proposta para Base Nacional Comum da Formação de Professores da Educação Básica. 2019. Disponível em: <http://portal.mec.gov.br/docman/dezembro-2019-pdf/135951-rcp002-19/file>. Acesso em: 6 ago. 2020.

BRASIL. Ministério da Educação. Proposta para Base Nacional Comum da Formação Continuada. $2020 . \quad$ Disponível em: <https://formacaoprofessordotcom.files.wordpress.com/2020/05/parecer_fcd_cne_maio_2020 .pdf>. Acesso em: 12 set. 2020.

CONTRERAS, José. A autonomia de professores. São Paulo: Cortez, 2002.

CNE (Conselho Nacional de Educação) (2019a). Resolução lei 14.040- 2020 define as Diretrizes Nacionais para a implementação dos dispositivos da Lei $n^{\mathbf{0}} \mathbf{1 4 . 0 4 0 / 2 0 2 0}$, que estabelece normas educacionais excepcionais a serem adotadas durante o estado de calamidade pública reconhecido. Recuperado de: 
〈https://drive.google.com/file/d/1jrZLd8aI5VQLgutfNwTR3ZW3BqFsAzE8/view〉. Acesso em: 29 set 2020.

DANTAS, Tiago. Web 2.0. Brasil Escola. Disponível em: <https://brasilescola.uol.com.br/informatica/web-20.htm>. Acesso em: 20 set. 2020.

DICIO: Significado de Ressignificar. 2020. Disponível em: <https://www.dicio.com.br/ressignificar/>. Acesso em: 29 set. 2020.

DUDENEY, Gavin; HOCKLY, Nick; PEGRUM, Mark. Letramentos digitais. Tradução Marcos Marcionilo. São Paulo: Parábola, 2016.

KUMARAVADIVELU, Bala. 2012. Individual identity, cultural globalization and teaching English as an international language: the case for an epistemic break. In: ALSAGOFF, Lubna; RENANDYA, Willy A.; HU, Guangwei; MCKAY, Lee S. (Ed.). Teaching English as an international language: principles and practices. New York: Routledge, 9-27.

LEFFA, Vilson José. A linguística aplicada e seu compromisso com a sociedade. Trabalho apresentado no VI Congresso Brasileiro de Linguística Aplicada. Belo Horizonte: UFMG, 711 de outubro de 2001. Disponível em: <http://www.leffa.pro.br/textos/trabalhos/ la_sociedade.pdf>. Acesso em: 29 ago. 2020.

LEFFA, Vilson José. Gamificação no ensino de línguas. Perspectiva. v. 38, n. 2, p. 01-14, 2020.

MENEZES DE SOUZA, L. M. T. O professor de inglês e os letramentos do século XXI: Métodos ou ética? IN: JORDÃO, C. M.; MARTINEZ, J. Z.; HALU, R. C. Formação desformatada: práticas com professores de língua inglesa. Campinas: Pontes editores, 2011. p. 279-303.

NASCIMENTO, Ana Karina de Oliveira; SANTOS, Giulia Pereira; SILVEIRA, Thalia dos Santos Silveira. Letramentos digitais e formação inicial de professores: entre ser discente e tornar-se docente. Revista (Com)Textos Linguísticos, v. 13, n. 26, 2019.

ROJO, Roxane; MOURA, Eduardo (Org.). Multiletramentos na escola. São Paulo: Parábola Editorial, 2012.

SAVIANI, Demerval. Formação de professores no Brasil: dilemas e perspectivas. Poíesis Pedagógica - V.9, N.1 jan/jun. p.07- 19, 2011.

SIGNIFICADO de Ethos: O que é ETHOS. 2015. Disponível em: <https://www.significados.com.br/ethos/>. Acesso em: 29 maio 2020.

Reconhecimentos: Nossos mais sinceros agradecimentos aos professores de línguas do DF que participaram deste estudo. 
Recebido em: 17/05/21

Aprovado em: 14/06/21

Revista Devir Educação, Lavras-MG. Edição Especial, p.29-52, Set./2021. 